https://doi.org/10.15407/ufm.22.04.539

V.L. KARBIVSKYY*, V.V. ZAIKA**,

L.I. KARBIVSKA, N.A. KURGAN, and N.O. ZUEVA

G.V. Kurdyumov Institute for Metal Physics of the N.A.S. of Ukraine, 36 Academician Vernadsky Blvd., UA-03142 Kyiv, Ukraine

*karb@imp.kiev.ua, ** zaikavladimir228@gmail.com

\title{
STRUCTURAL AND PHYSICAL PROPERTIES OF ULTRATHIN BISMUTH FILMS
}

Bismuth films are interesting objects for research because of the many effects occurring when the film thickness is less than $70 \mathrm{~nm}$. The electronic band structure changes significantly depending on the film thickness. Consequently, by changing the film thickness, it is possible to control the physical properties of the material. The purpose of this paper is to give a brief description of the basic structural and physical properties of bismuth films. The structural properties, namely, morphology, roughness, nanoparticle size, and texture, are discussed first, followed by a description of the transport properties and the band structure. The transport properties are described using the semi-metal-semiconductor transition, which is associated with the quantum size effect. In addition, important characteristic is a two-channel model, which allows describing the change in resistivity with temperature. The band structure of bismuth films is the most interesting part due to the anomalous effects for which there is still no unambiguous explanation. These effects include anomalous spin polarization, nontrivial topology, and zone changes near the edge of film.

Keywords: bismuth thin films, band structure, Rashba effect, transport properties, anomalous spin polarization.

\section{Introduction}

Recently, bismuth films have attracted increased interest due to their unusual properties, such as high charge mobility [1], the Rashba effect [2], quantum-dimensional effects [3], high Hall coefficient [4], and others. In addition, the study of bismuth films is also relevant from the

Citation: V.L. Karbivskyy, V.V. Zaika, L.I. Karbivska, N.A. Kurgan, and N.O. Zueva, Structural and Physical Properties of Ultrathin Bismuth Films, Progress in Physics of Metals, 22, No. 4: 539-561 (2021) 
practical point of view for applications in spintronics [2, 5], microelectronics, and optoelectronics [6-11]. Bismuth-containing films are also used as topological insulators [12]. Many of the above-mentioned applications and exotic properties depend on the quality of the films obtained and their subsequent processing. That is why many researches are devoted to film production and processing methods [6, 13-26].

Thus, it is necessary to study further the processes of obtaining films, as well as their properties. First of all, it is worth paying attention to the structural properties, as well as to the shape and quality of the surface. Since the properties of the obtained films can vary greatly due to different surface morphology or the presence defects.

Bismuth films can be used to create new devices. For example, we can mention a single-component rectifier diode [27], a planar hall sensor [28], and elements of terahertz technologies [29].

The properties of thin films can be divided into two main categories. The first category includes structural properties, namely porosity, roughness, thickness, surface shape, and others. The second category includes properties such as electrical conductivity, transparency, magnetization, electronic structure, etc.

The aim of the paper is to generalize and describe the properties of bismuth films regardless of the method of their production.

\section{Structure}

\subsection{Surface Morphology and Roughness}

In [36], a bismuth monolayer was obtained on a silicon substrate. The authors found that the surface consists of two phases. The first phase had a bee honeycomb structure. The second phase had a hexagonal dense packing. In the initial stages of growth, the bismuth monolayer repeats the structure of the substrate. The films had a smooth surface and the surface roughness was less than a few pm. turning to roughness, it is worth mentioning the work of Payer and colleagues [37], where the effect of annealing on morphology and roughness was studied. In this paper, annealing had a positive effect on the roughness value and the quality of the films. It was also shown using atom force microscopy (AFM) that the surface was composed of many pyramids. After annealing of this film, the surface morphology changed dramatically and became almost atomically flat. At the same time, the films were no longer textured or polycrystalline. The films after annealing had the same constant lattice and structure as the substrate. Thus, the structure of the substrate affects the structure of films up to $20 \mathrm{~nm}$ thick. The Payer results showed that the quality of the films improved during annealing up to $240{ }^{\circ} \mathrm{C}$. Further increases in temperature are not recommended because the quality of the films deteriorates. 
Among other works stands out [38], where quasi-crystalline bismuth thin films were grown. It was shown that the bismuth atoms are deposited in certain positions in order to reproduce the structure of the substrate. This demonstrates again the influence of the substrate structure on the film structure in the initial stages of bismuth film growth. Atoms bond with each other in different layers, although though they do not interact with each other in the same monolayer. It was also shown that both crystalline and quasi-crystalline phases grow at the same time (small film thicknesses up to $15 \mathrm{~nm}$ are characterized by low film density).

In the paper [39], three bismuth films with thicknesses of $11 \mathrm{~nm}, 21 \mathrm{~nm}$ and $78 \mathrm{~nm}$ were investigated. The $11 \mathrm{~nm}$-thick films had a discontinuous structure and many voids with spaces up to $10 \mathrm{~nm}$. The $21 \mathrm{~nm}$ thick films had essentially no voids anymore, and the $78 \mathrm{~nm}$ thick films had no voids. The morphology of the film affects its properties. As the authors of this work note, this is especially noticeable for the dielectric function as the film thickness increases from $11 \mathrm{~nm}$ to $17 \mathrm{~nm}$. In [40], the change in film morphology with increasing thickness was investigated. The results are very similar to those of the previous paper, but the transition from discontinuous to homogeneous film occurred at a different thickness. It was also shown that the roughness of the films increased with increasing film thickness. The authors of the research explain this by the fact that the grains in the film grow faster in the vertical direction than in the horizontal.

The effect of the deposition angle on the structural properties of the film was studied in this work [41]. Films deposited at a normal angle grew faster than those deposited at an oblique angle did. In addition, AFM showed that films deposited at a normal angle had a more homogeneous morphology. Most likely, this feature is related to the selfdarkening effect for the films obtained at an oblique angle. The roughness value also appeared to be lower for the films obtained at a normal angle of $21 \mathrm{~nm}$ versus $29 \mathrm{~nm}$ for the oblique angle.

The authors of [42] studied bismuth films at the initial stages of deposition and found that the films grow by the Stranski-Krastanov mechanism. The authors also found that when coating the surface with less than 1 monolayer, the film self-organizes into cluster arrays with periodicity $(5 \times 5)$, as well as having a superstructure $(\sqrt{37} \times \sqrt{37}) \mathrm{R}^{\circ} 5^{\circ}$.

In [43] there is a comparison of films obtained by different methods. Figure 1, $a$ shows films obtained by thermal deposition. It can be seen that the film surface consists of triangles of different shapes. Figure 1, $b$ shows films produced by magnetron sputtering at constant current. It is clear that the film surface is composed of huge crystals with sizes greater than $100 \mathrm{~nm}$. Figure 1, $c$ shows the films obtained by radiofrequency magnetron sputtering. On the surface, you can see the same 

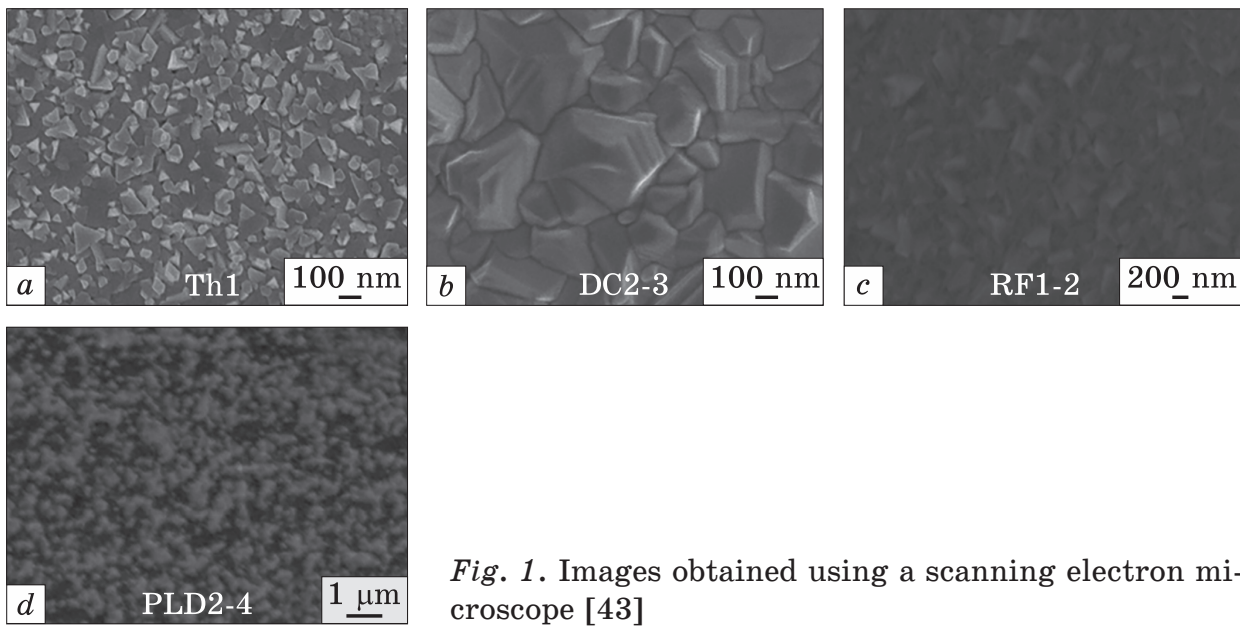

Fig. 1. Images obtained using a scanning electron microscope [43]

Fig. 2. Roughness of bismuth films obtained at different substrate temperatures [25]

large crystals, but smaller than in the case of $b$. Finally, Fig. $1, d$ shows films obtained by pulsed laser sputtering films had a granular surface.

The effect of the substrate temperature on the morphology and roughness of the films was inves-

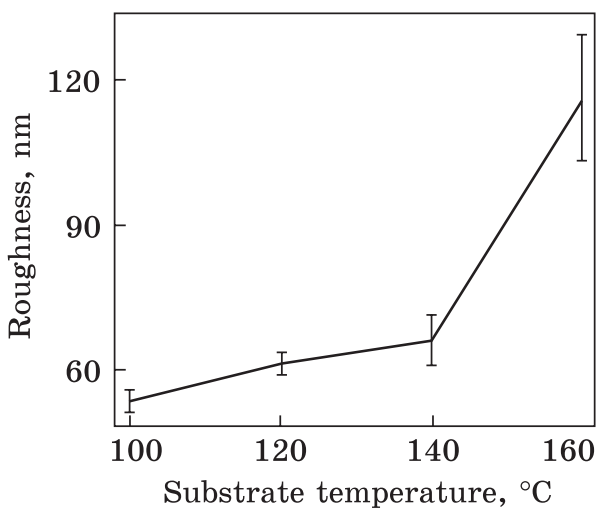
tigated in [44]. With increasing temperature, the roughness decreased due to the fact that the large grains on the surface became smaller and smoother $\left(10-110^{\circ} \mathrm{C}\right)$. It was also found that at temperatures above $110^{\circ} \mathrm{C}$ the film growth mechanism changes from a layer-by-layer to an island mechanism and the grain boundaries become clearly visible. In [45] the effect of the substrate temperature on the film morphology was also investigated but in a wider temperature range. When the films were deposited on the substrate at room temperature, the films were continuous, with grains of different sizes. At $100^{\circ} \mathrm{C}$, the films were continuous, but the grains became larger. When the temperature reached $130^{\circ} \mathrm{C}$, the films became discontinuous with many polyhedrons of different shapes. With further increase in temperature, the grains on the surface were almost spherical in shape with different sizes. In the temperature range from 250 to $300^{\circ} \mathrm{C}$, the clusters on the surface began to decrease as the temperature increased. The highest roughness of the films was at the temperature of $100^{\circ} \mathrm{C}$. As noted by the authors, in the 
temperature range from 160 to $250^{\circ} \mathrm{C}$ the roughness did not change significantly, although the morphology of the films changed considerably. To conclude our consideration of the affecting substrate temperature on the film morphology, it is worth examining the work [25]. The changes in surface shape are similar to those discussed above. The roughness is shown in Fig. 2 [25]. For films with a thickness of $3.7 \mu \mathrm{m}$, the roughness of the films obtained was in the range from 9 to $14 \mathrm{~nm}$ with an average grain size from 50.2 to $52.8 \mathrm{~nm}[46]$.

\subsection{The Size of the Structural Elements}

In work [40], films with a thickness of $9.3 \mathrm{~nm}$ had a round grain shape with a diameter of less than $50 \mathrm{~nm}$. When the thickness was increased to $12.4 \mathrm{~nm}$, the grains coalescence with neighbouring grains and the shape of the grains changed from a round to an elongated shape. At a film thickness of $19 \mathrm{~nm}$, the grains became polyhedral in shape. Grains of different shapes with a height of more than $50 \mathrm{~nm}$ and a width of about $100 \mathrm{~nm}$, as well as with a height of $10 \mathrm{~nm}$ and a width of $200 \mathrm{~nm}$, are characteristic of thicker $44 \mathrm{~nm}$ films. Similar results were obtained in [45]. However, it is worth adding that when the film thickness was increased from $21 \mathrm{~nm}$ to $78 \mathrm{~nm}$, the grain sizes in the plane changed from $50-150 \mathrm{~nm}$ to $100-200 \mathrm{~nm}$.

Figure 3 shows the dependence of grain size on film thickness, as well as the ratio of grain size to film thickness [47]. The difference in grain sizes with those described above is due to the fact that, after the application of these films, annealing was used (since with increasing temperature the surface diffusion increases, so the coalescence of the grains reduces the surface energy). It can be seen from Fig. 3 that the grain size increases as the film thickness increases. While the ratio of grain size to film thickness decreases.

The influence of oblique angle deposition on crystal size was evaluated [41]. X-ray diffraction showed that the crystal sizes were smaller at $70 \mathrm{~nm}$ tilt deposition versus $111 \mathrm{~nm}$ normal deposition, and it should be noted that the film thickness was greater at normal deposition. In addition, the crystal sizes were estimated by FESEM and were $138 \pm 25 \mathrm{~nm}$ and $106 \pm 22 \mathrm{~nm}$ for normal and oblique deposition. These differences are explained by the fact that the XRD method used the Scherer formula, which gives the smallest crystal sizes.

The effect of the substrate temperature in the range from $18^{\circ} \mathrm{C}$ to $150^{\circ} \mathrm{C}$ on the size of the crystals was investigated in work [44]. As the temperature increased, the size of crystals increased, which is also consistent with the works [25, 45]. In its paper, the crystal size increased in the temperature range from $18^{\circ} \mathrm{C}$ to $70^{\circ} \mathrm{C}$, after which it did not change significantly. In the paper [45], in the temperature range from 


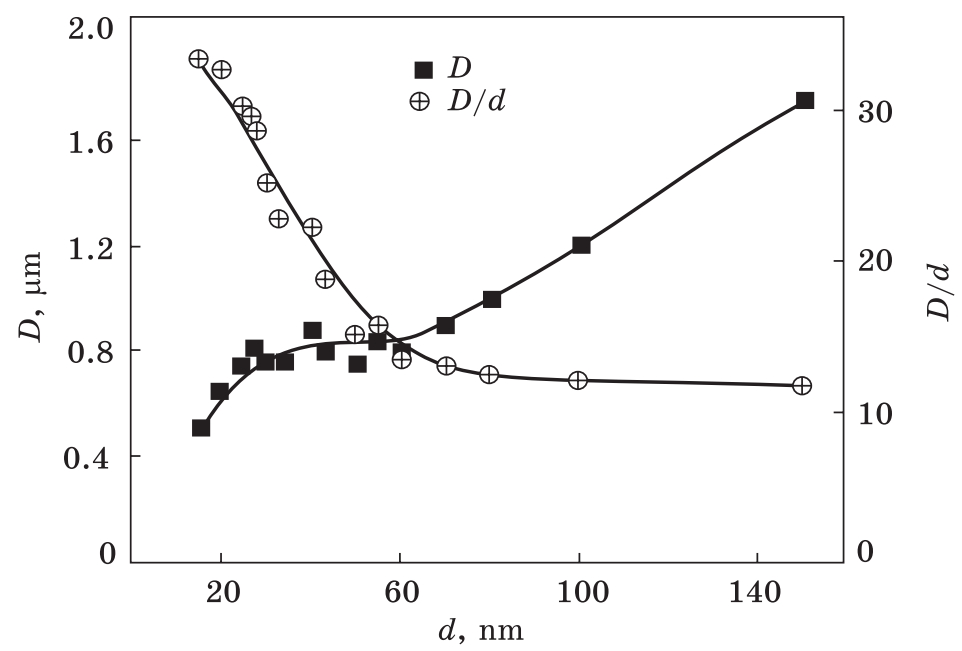

Fig. 3. Crystal size $D$ and the ratio of $D / d$ crystal size to film thickness [47]

$40^{\circ} \mathrm{C}$ to $100^{\circ} \mathrm{C}$ the crystal size remained constant, while from $100^{\circ} \mathrm{C}$ to $160^{\circ} \mathrm{C}$ the crystal size increased. In work [25], the crystal sizes increased in the range from $100^{\circ} \mathrm{C}$ to $160^{\circ} \mathrm{C}$. Thus, it can be concluded that a temperature of $100^{\circ} \mathrm{C}$ is sufficient for active diffusion in bismuth films. In [45], oscillations in the crystal sizes are observed in the temperature range from $160^{\circ} \mathrm{C}$ to $250^{\circ} \mathrm{C}$. The authors suppose that these oscillations can be caused by the oxidation of the bismuth films.

In [48] was investigated films were grown at different rates. The surface of the films grown at different deposition rates was shown using STM. The difference in the size of the nanoparticles is not significant, although the films grown at a higher deposition rate had a little smaller grain sizes.

In work [37], bismuth films of $20 \mathrm{~nm}$ thickness were investigated. The particles were pyramidal shapes with a width from 20 to $100 \mathrm{~nm}$ and a height up to $4 \mathrm{~nm}$. After annealing at $200^{\circ} \mathrm{C}$, the films were neither polycrystalline nor textured. Instead, the film had the same lattice constant and hexagonal orientation as the substrate.

In the study, the effect of light during film deposition was studied [49]. Films obtained in the dark had a surface shape form of not large rounded islands with an average value of $7.3 \pm 0.7 \mathrm{~nm}$. The films which were deposited with pre-illumination of the substrate had similar morphology and $8.2 \pm 1.2 \mathrm{~nm}$. Finally, the films obtained by chemical deposition had elongated islands in height with a roughness of $15.8 \pm 0.6 \mathrm{~nm}$. The film had a rhombohedra structure of metallic bismuth. 


\subsection{Textured Growth}

Using XRD, it was found that the films grow mainly in two directions (003) and (012) (hexagonal system) at room temperature on the glass substrate [45]. Weak peaks (104) (110) (015) (006) (024) (122) are also noticeable. With increasing temperature, the intensity of peak (003) decreased, while (012) increased, as confirmed by [44]. Peaks (006) and (009) were also present in $[41,44]$. As the temperature increased to $150^{\circ} \mathrm{C}$, the peaks $(001)$ dissolved, leaving only peaks (012) and (024). The change in the textured coefficient with temperature is shown in Fig. 4. It is noticeable that with increasing temperature the intensity of peaks, group (001) to which (003) (006) and (009) belong, decreases. At the same time, the textured coefficient of a group (012) increases to which peaks (012) and (024) belong. As suggested by the authors of [44], these changes in preferred orientation may be related to changes in surface energy. Since for planes (001) the atoms have three covalent bonds, while the (012) plane has two covalent bonds and one unpaired bond on the surface.

Bismuth films on a silicon substrate also show a preferred orientation along the direction of (003) (006) and (009) [50]. The authors of [51] also observed peaks (003) (006) and (009), and a small peak (012). It is worth noting that the substrate temperature in this experiment was $150^{\circ} \mathrm{C}$. The effect of film thickness on texturization was also studied [40]. The peaks of the (001) group became noticeable starting from the thickness of $13.8 \mathrm{~nm}$, and gradually increased with increasing film thickness.

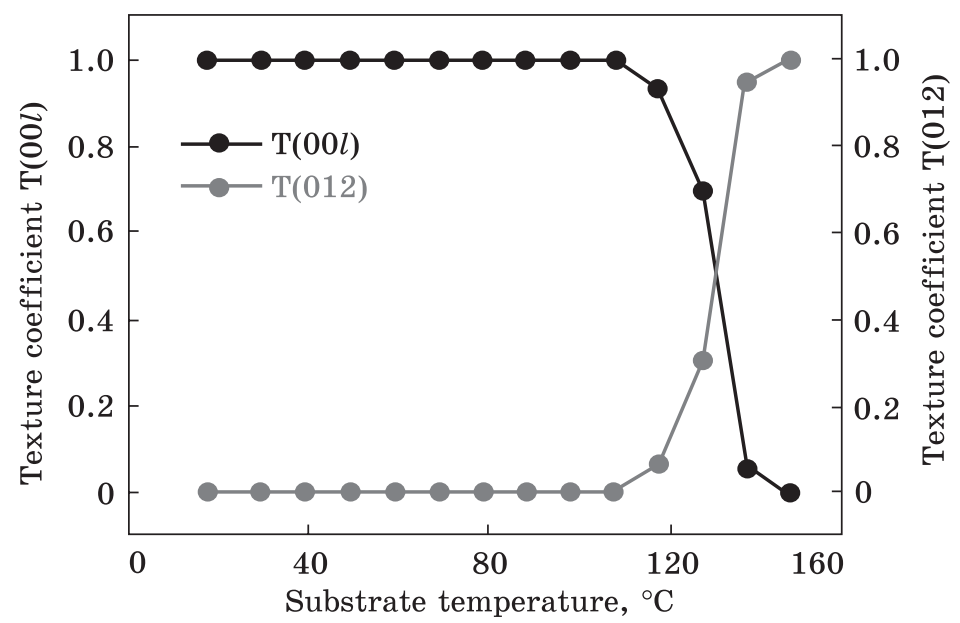

Fig. 4. Variation of the textured coefficient with changes in the substrate temperature [44] 


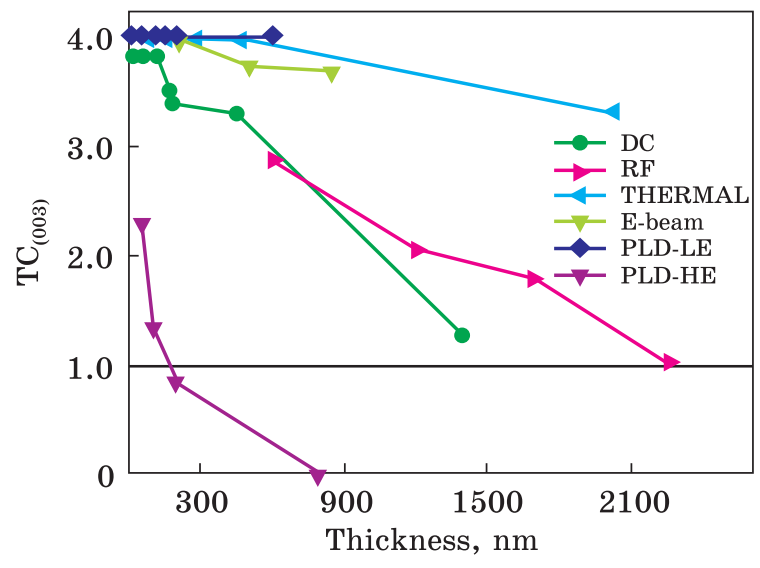

Fig. 5. Value of texture factor for (003) orientation as a function of film thickness. TC(003) equal to 4 means unique orientation, $\operatorname{TC}(003)=1$ means random orientation as in powder samples, and $\mathrm{TC}(003)=0$ means that peak (003) is not observed [43]

In [43] films were obtained using different sputtering methods magnetron sputtering, evaporation and pulsed laser sputtering (PLD). It is also shown that with thermal evaporation and electron evaporation the films, regardless of thickness, grow in the direction (003); Fig. 5. Whereas with pulsed laser sputtering, the films grew in direction (012), which is probably due to the high energy of arriving ions. The growth in direction (003) is explained by the most energetically advantageous growth mode, while the growth in direction (012) is associated with an increase in energy of arriving atoms and as consequence mobility. In [52] bismuth films were deposited on an yttrium-iron-garnet substrate. Peaks (003) (006) and (009) were noticeable for $20 \mathrm{~nm}$ thick films, and the peak (104) was also observable.

\section{Electron Transport Properties}

\subsection{Resistance and Magnetoresistance}

The resistivity of bismuth thin films $52 \mathrm{~nm}$ thick decreased with increasing temperature [51]. This resistance behaviour indicates the semiconductor properties of the films, although it is known that the resistance of bulk bismuth behaves like metal [53]. Next, it is worth considering the work [54], where nanoribbons were investigated. The resistance of nanoribbons with a thickness of $40 \mathrm{~nm}$ decreased with increasing temperature. For nanoribbons with a thickness of $80 \mathrm{~nm}$, the resistance increased with increasing temperature. The dependence of resistance behaviour from film thickness is related to quantum-dimensional effects [55]. In [27], the resistance of films of different thicknesses was also studied. For films with a thickness of $5.7 \mathrm{~nm}$, the resistance with temperature changes exhibited a semiconductor-like behaviour. While for 28-nm-thick film, the resistance behaves like in semimetal. In [56], bismuth films with a sublayer and a $10 \mathrm{~nm}$ coating 
Fig. 6. Temperature dependence of the resistance of bismuth films with a thickness of $19 \mathrm{~nm}$ [44]

of antimony films were investigated. The $90 \mathrm{~nm}$ thick films had higher resistance than the $650 \mathrm{~nm}$ thick films. For the $650 \mathrm{~nm}$ films, the resistance increased regardless of the position of the antimony film. Although for the $90 \mathrm{~nm}$ bismuth films, the antimony sublayer decreased the resistance. Regardless of the film thickness, the resistance decrea-

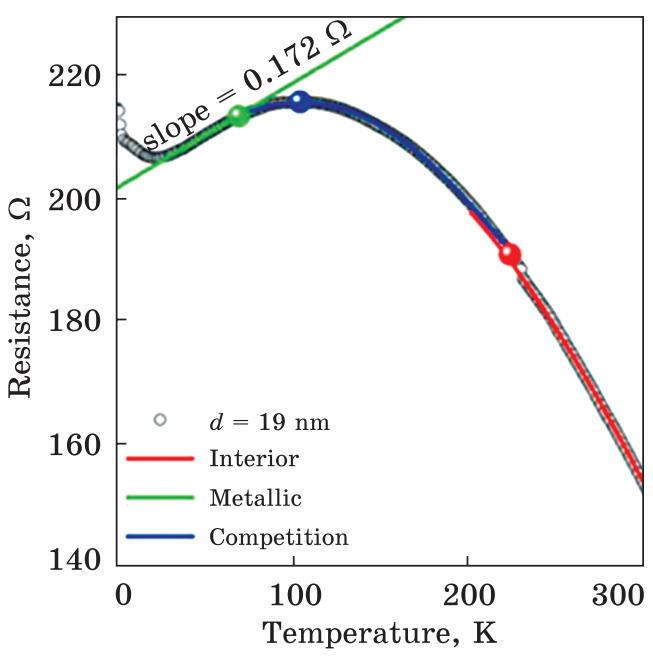
sed with increasing temperature.

Another interesting semi-metal-semiconductor transition can be observed with temperature change [44]. Figure 6 shows the dependence of resistance with temperature change. To explain this dependence, the authors used a two-transport model [44]:

$$
R^{-1}=(A+B T)^{-1}+\left(C \exp \left(\frac{\Delta E}{2 k_{B} T}\right)\right)^{-1}
$$

with coefficients $A, B$, and $C$. The first term of the formula corresponds to metallic conductivity and the second to semiconductor conductivity. The Red line corresponds to semiconductor conductivity. The green line corresponds to metallic conductivity. Meanwhile, in the blue zone, there is a competition between semiconductor and metallic type conductivity. What is interesting is that the temperature at which the films have maximum resistance has a linear relationship to the thickness of the film. The thicker the film, the closer to absolute zero the transition temperature is.

It has been shown that the surface resistance decreases with increasing film thickness [40]. Figure 7 shows the result of this study. The sharp drop in surface resistivity in the region from 10 to $15 \mathrm{~nm}$ is explained by the fact that the grains on the surface connect and form an electrical channel. The drop in resistance around $18 \mathrm{~nm}$ is due to the final filling of the voids in the film. The surface resistivity also decreased with thickness [52], but less sharply. These differences may be due to different types of a substrate as well as to differences in surface quality. S.A. Stanley and colleagues showed that the sputtering power does not significantly affect the surface resistance, while the pressure has a noticeable result [48]. In addition, S.A. Stanley studied the effect of 


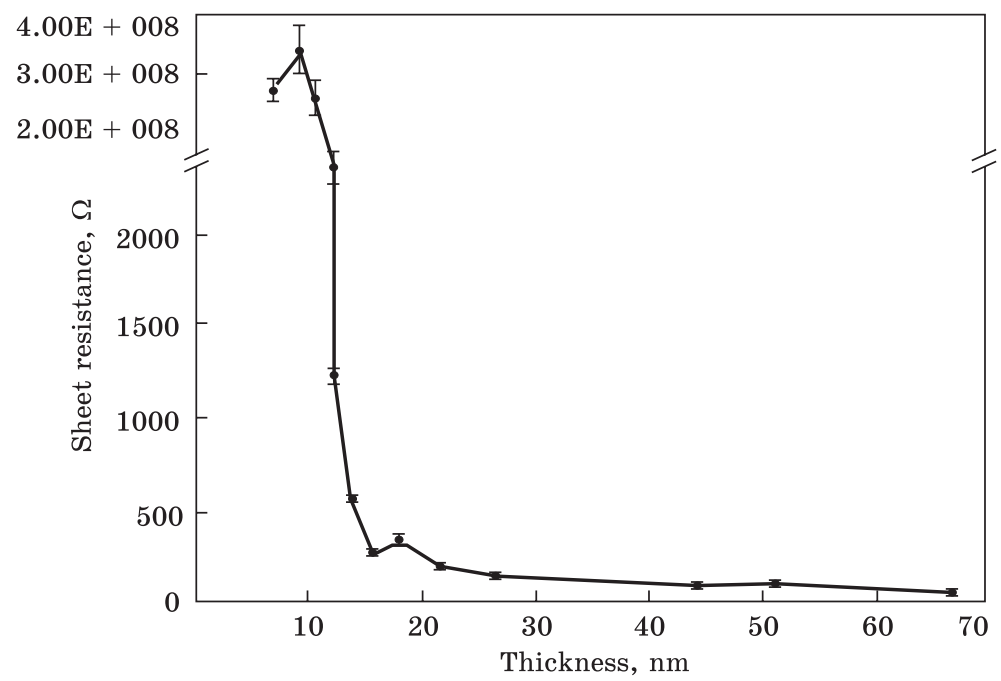

Fig. 7. Variation of the surface resistivity with changes in the film thickness [40]

substrate temperature on surface resistance. From room temperature to $160{ }^{\circ} \mathrm{C}$, the surface resistance decreased. Although at a temperature of $90{ }^{\circ} \mathrm{C}$ the resistance increased insignificantly, which is due to the deterioration of the texture of the film. The researchers suggested that the decrease in surface resistance might be due to an increase in charge mobility.

At low temperatures, the magnetoresistance (MR) depends on the film deposition rate [44]. At $2 \mathrm{~K}$, the MR for films deposited at rate $0.19 \AA /$ min grew twice as fast as for films obtained at rate $1.61 \AA / \mathrm{min}$. This is due to the smaller grain size for the films with a lower growth rate. At room temperature, the differences in MR were not significant. It is worth noting that at room temperature the MR dependence from the magnetic field was parabolic, while for $2 \mathrm{k}$ it was linear. In the following paper, the MR was investigated in two configurations at different temperatures [57]. In the first configuration, the angle between the magnetic field and the current was changing. In this case, as expected, the minimum value of MR was achieved when the direction of the magnetic field and current coincided. Further, as the angle between the current and the magnetic field increased, the MR increased and reached its maximum values when the current and the field were perpendicular. As the temperature increased, both the maximum and minimum MR values were lower. In the second configuration, the field was oriented normally to the current, while the angle between the field and the film changed. Thus, the contribution from scattering at the surface and at the grain boundaries was investigated. That is, when the films are orien- 

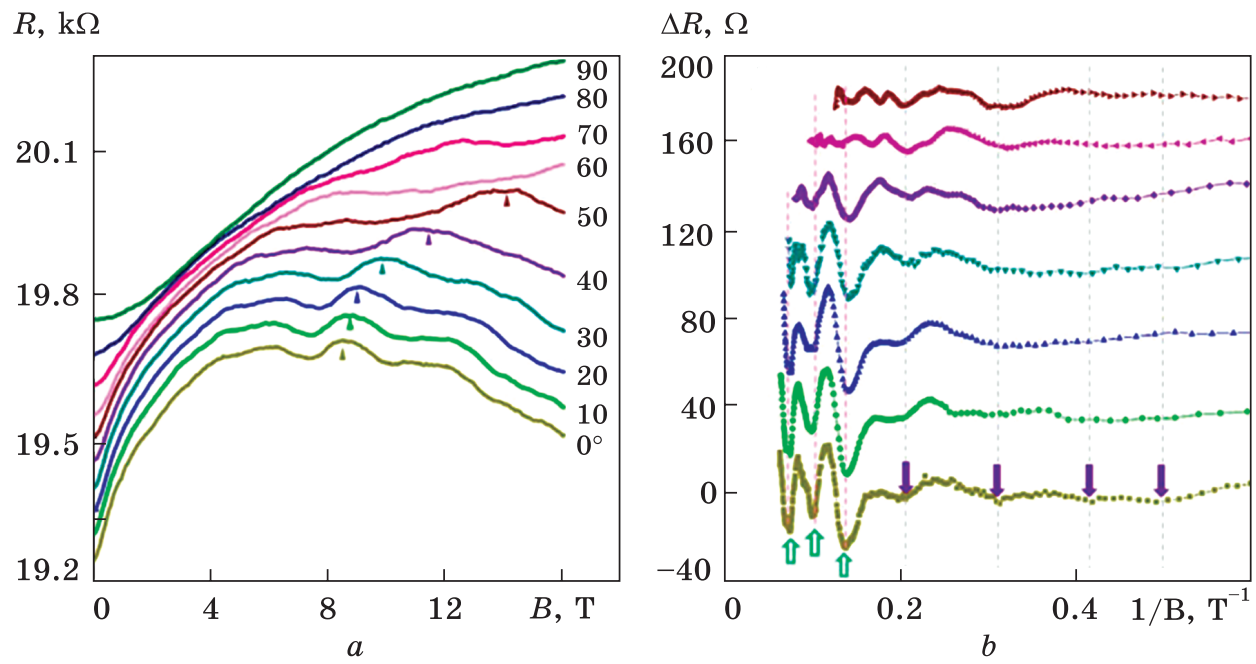

Fig. 8. (a) Resistance of $40 \mathrm{~nm}$ thick bismuth films as a function of the magnetic field at different angles between current and field at $2 \mathrm{~K}$. (b) Resistance oscillation amplitude as a function of the inverse field [54]

ted normal to the field, scattering at the grain boundaries dominates. Moreover, when the films are parallel to the field, the scattering on the surface is dominant. Maximum MR was reached when films were oriented perpendicular to the field. It was also found that with decreasing film thickness the ratio of maximum and minimum resistance decreases, which corresponds to the research [52]. This feature is related to scattering on the surface. It was also shown that the ratio of the maximum and minimum MR values is different for textured and non-textured films [57]. The authors carried out very interesting reasoning, after which the experiment was set up. It turned out that it is related to the anisotropic effective mass of electrons.

Two-dimensional Shubnikov-de Haas oscillations were also observed [54]. Figure $8(a)$ shows the resistance of nanoribbons, $(b)$ the resistance of nanoribbons after subtraction of the smooth background. As the authors note, the positions of the maxima and minima depend only on the perpendicular component of the field. It was also shown that the amplitude of oscillations decreases with increasing temperature. In addition, the authors showed that the surface states remain stable even after a week in the air.

\subsection{Electrical Conductivity and Charge Carriers}

From low temperatures, the conductivity decreased with increasing temperature for all films [58]. Which corresponds to the above described semimetal-semiconductor transition [44]. Further, with increasing tem- 

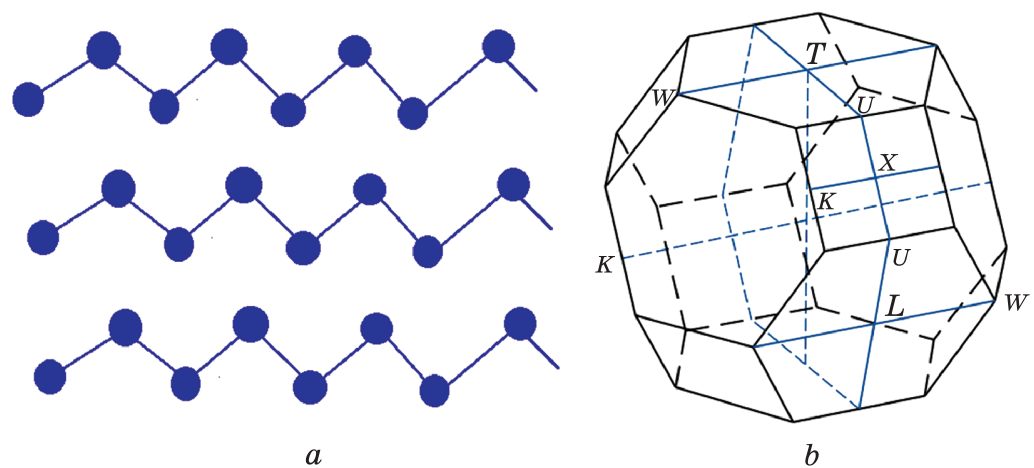

Fig. 9. (a) The left image is bismuth film bilayers. (b) On the right, the Brillouin zone [64]

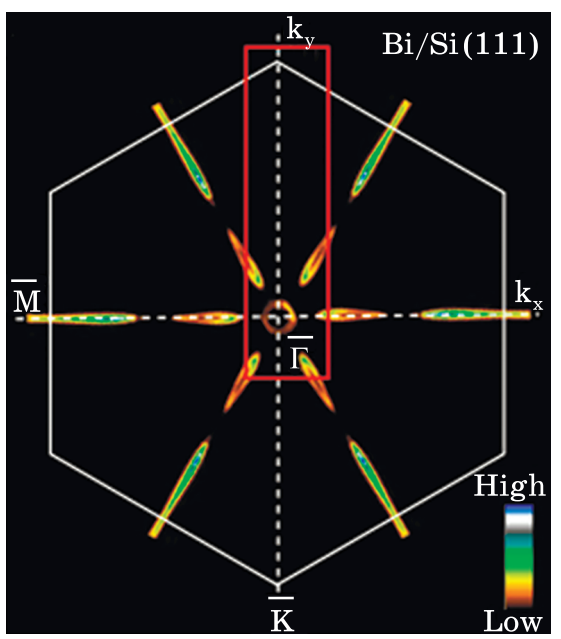

Fig. 10. Fermi surface [65]

perature, the conductivity of films of different thicknesses had a different dependence on temperature. For thinner films, the conductivity degraded. This may be due to a wider band gap width for thinner films. This behaviour may also be related to the percolation effect [59] due to the fact that the films did not completely cover the surface of the substrate. Switching to thicker films, their conductivity increased with increasing temperature. This was caused by a decrease in the band gap width. Further, to obtain quantitative results, the conductivity was represented as a sum of two components, the first of which was responsible for metallic conductivity and the second for semiconductor conductivity. Therefore, at low temperatures, the contribution to the conductivity is given mainly by the metallic part. It was found that the width of the band gap has an inverse dependence with film thickness $E_{\mathrm{g}}=1 / t$, which is also confirmed in [22, 27]. Consequently, the semiconductor contribution to conductivity begins to dominate with an increase in film thickness as well as temperature. Conductivity had almost square dependence on film thickness $G=d^{1.8}$. In [41] it was shown that the conductivity of films applied at a right angle was almost two times higher than at the oblique angle. The conductivity also improved with temperature increase.

In addition to the above, the mobility and concentration of charge carriers were evaluated in [58]. The concentration and mobility of the 
charge carriers increases with increasing film thickness. However, these characteristics may not coincide for thicker films due to the greater contribution from bulk states than from surface states. For $3.2 \mathrm{~nm}$ and $5.7 \mathrm{~nm}$ thick films, mobility decreased with increasing temperature [27], while carrier concentration increased. It was also shown that for films $28 \mathrm{~nm}$ thick, the carrier concentration almost did not change with temperature. In another study, it was shown that the mobility of charge carriers did not differ significantly between textured and non-textured films [57].

\section{Band Structure}

In this section, the thickness of the films will be expressed through the number of bismuth bilayers. Where 1 bilayer $(\mathrm{BL})=3.93 \AA$ [60]). Without a doubt, the band structure of bismuth films is one of the most interesting topics for discussion in solid-state physics. Many studies have been devoted to the study of the topological structure of bismuth films, both theoretical and experimental [5, 30, 34, 35, 61-63]. Figure 9 shows the bismuth BL as well as the Brillouin zone [64].

\subsection{Fermi Surface}

Figure 10 shows the Fermi surface [65], where different surface states can be observed. In the centre near point $\bar{\Gamma}$, the hexagon refers to the electron pocket. Further, elongated ellipses near the hexagon refer to hole pockets, while ellipses near points $\bar{M}$ refer to electron pockets, that is consistent with [66]. In [66] it is shown that the pocket near point $\bar{M}$ has an electron-like dispersion with a lower energy value of $0.03 \mathrm{eV}$ below the Fermi energy. Akari Takayama [66] also attributes hole bands to the quantum well state (QWS), which arise due to quantization in the direction normal to the film plane.

\subsection{The Rashba Effect and Anomalous Spin Polarization, Surface States}

Figure 11 shows the zone structure of 40BL thick bismuth films, as well as the Fermi surface [2]. The spin polarization was also measured. At points $B$ and $B$ ' the predominant spin up, while at points $A$ and $A^{\prime}$ spin down. Additionally, the authors noticed that, due to the quantitative difference in polarization in the plane of film, this effect cannot be attributed to the normal Rashba effect. An anomalous spin polarization with respect to the film normal was also shown, which had been found earlier in [67]. Thus, this is inconsistent with the description of the normal Rashba effect. In addition, it was noticed that the polarization of $\mathrm{P}_{\mathrm{y}}$ also decreases with thickness. It was shown that crossing the $\bar{\Gamma}$ point the spin polarization changes its direction, which you can read more about in [3, 

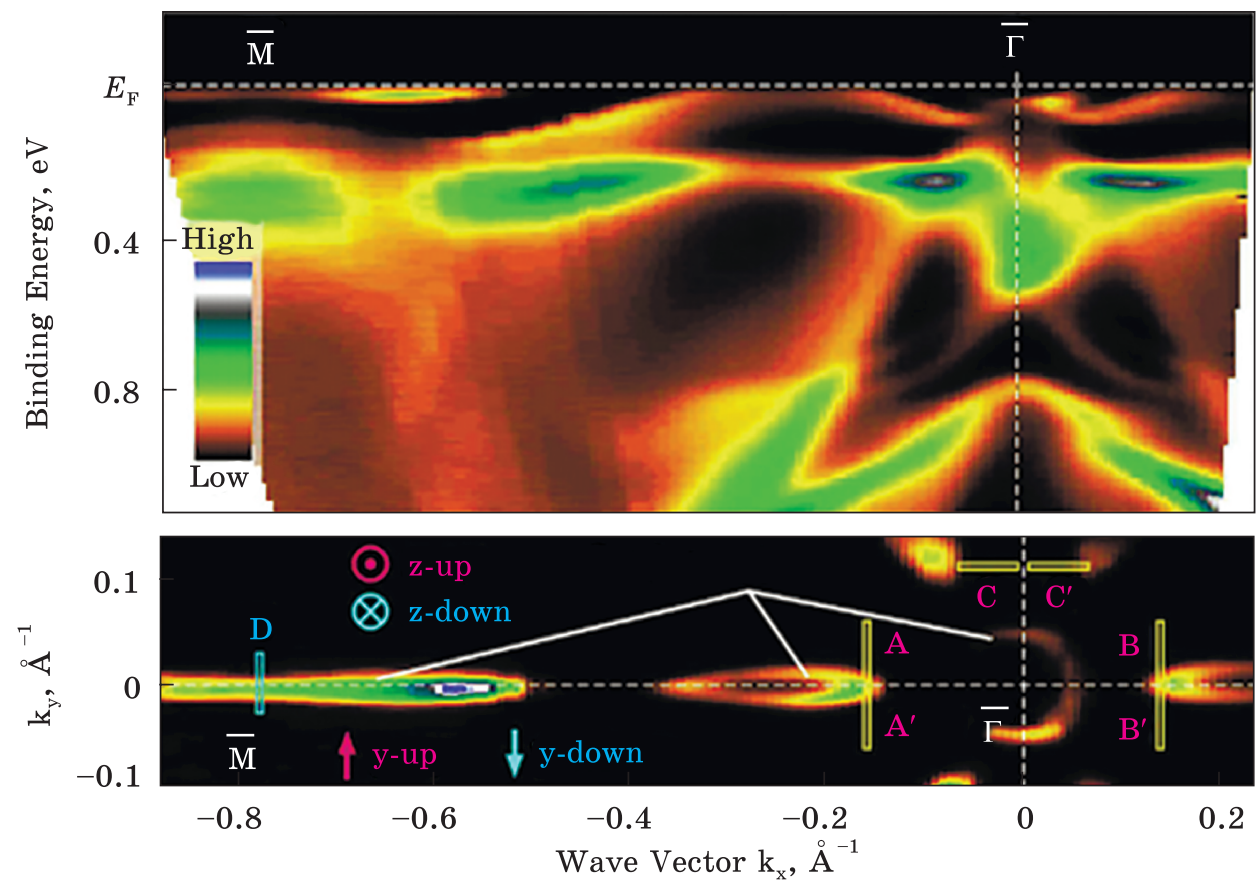

Fig. 11. Band structure of $40 \mathrm{BL}$ thick bismuth films, and below the Fermi surface [2]

67]. Using spin-resolved photoemission spectroscopy (SARPES), it was found that the metallic surface states are split in spin near point $\bar{\Gamma}$, but not near point $\overline{\mathrm{M}}$ [67]. In [66] they observed not only spin splitting near point $\bar{M}$, but also a change in spin polarization when passing through point $\bar{M}$. In addition, at the same paper was showed that the value of spin polarization depends on the thickness of the films, and can be negligible for film thicknesses below $8 \mathrm{BL}$. To explain this phenomenon, the authors assumed that the states induced by the Rashba effect are separable for the upper and lower layers. As the film thickness decreases, these states begin to overlap and mix with each other, so that they cannot subsequently be detected. The spin-orbital splitting for 1 monolayer (ML) of bismuth was also observed [68] due to the Rashba effect near point $\overline{\mathrm{M}}$. Thus contradicting the previous hypothesis about level splitting near point $\bar{M}$. In [69] it was shown that the surface states are split near point $\bar{\Gamma}$ but are not separable in point $\bar{\Gamma}$ itself. Perhaps the Rashba effect is caused by a change of potential in the normal to the surface direction [70].

\subsection{Division of Subzones}

A clear zone separation was shown for a thickness of $40 \mathrm{BL}$ [2]. As the film thickness decreased, the highest level shifted downward, and the distance between the levels increased, which is consistent with [71]. 

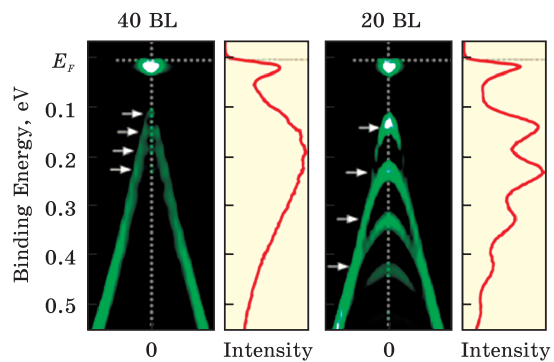
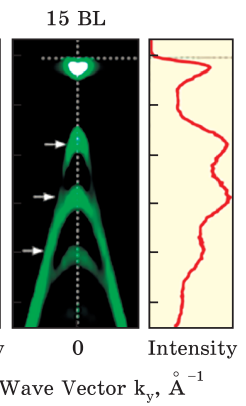

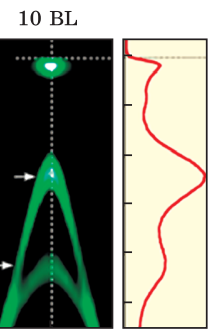

$0 \quad$ Intensity
$8 \mathrm{BL}$

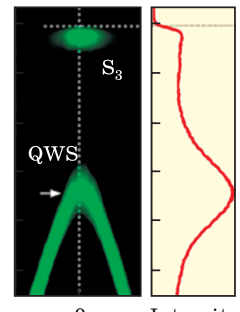

0 Intensity

Fig. 12. Band dispersion for films of different thicknesses [66]

Toru Hirahara assumes that QWS appears because the electrons inside the film sense the potential between the vacuum and the substrate [3]. Also in both works [2, 3], an increased quantity in QWS was observed with increasing film thickness. Figure 12 depicts the change in the band dispersion with the change in film thickness near the $\bar{M}$ point [66]. From Fig. 12 it is easy to see that with increasing film thickness the upper state of QWS shifts down from the Fermi level. It can also be seen that with increasing thickness the number of subbands increases, as well as the distance between them decreases, which is confirmed by [72]. T. Hirahara and colleagues [72] have shown that the separation between QWS becomes imperceptible above $180 \mathrm{BL}$ due to the fact that the splitting between the levels becomes too small. In [66] it is assumed that the QWS arise due to the quantization of bulk zones.

\subsection{A Non-Trivial Band Structure?}

At this stage, bismuth films are considered to have a non-trivial topology [5]. Figure 13 shows the band structure along $\bar{\Gamma}-\bar{M}$ directions [5]. Where only the first case refers to the non-trivial topology. Both branches of surface states are assumed to belong to the valence zone near point $\bar{\Gamma}$ [73]. S. Ito and others observed that the SS1 and SS2 branches are not degenerate near point $\overline{\mathrm{M}}$ thus indicating a non-trivial topology, although, for ultrathin films, their shape may change due to the interaction of the upper and lower layers [72].

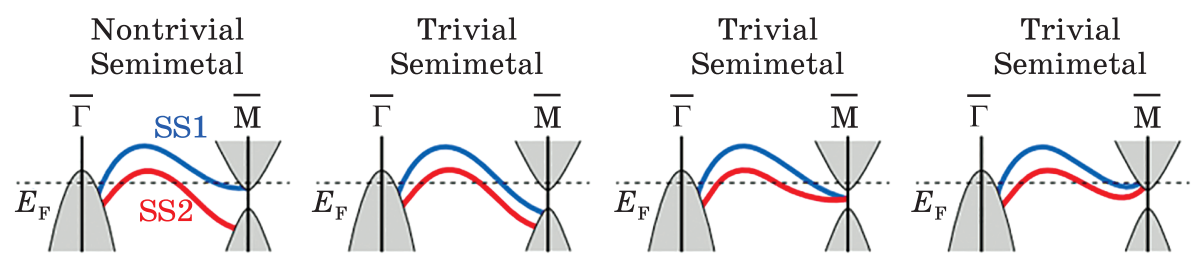

Fig. 13. Supposed band structure for bismuth films in the $\bar{\Gamma}-\overline{\mathrm{M}}$ direction. The red and blue lines correspond to the spin split surface states [5] 


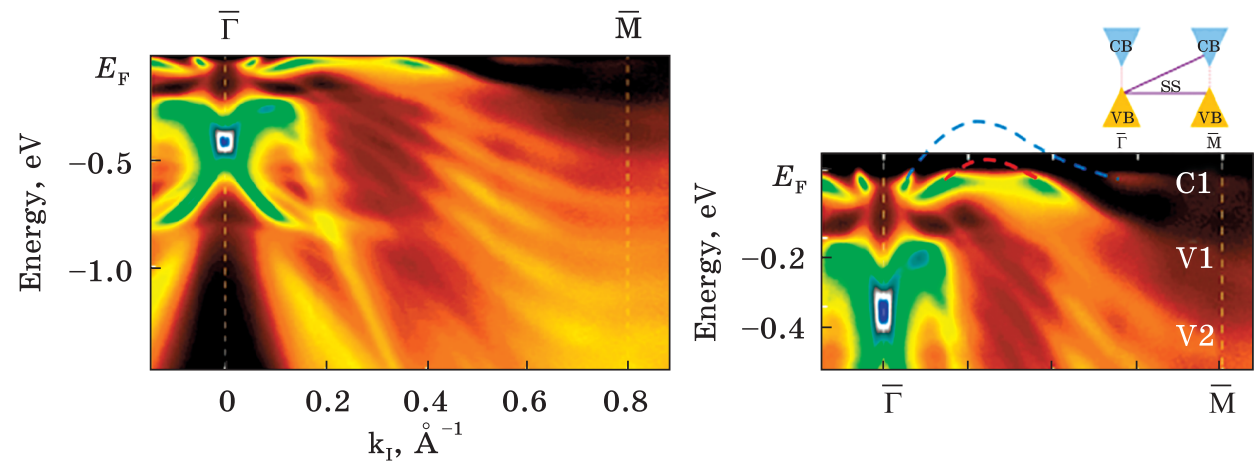

Fig. 14. Band structure of bismuth $20 \mathrm{BL}$ thin films in the $\bar{\Gamma}-\overline{\mathrm{M}}$ direction. On the right, enlarged image and zone connection diagram [34]

Figure 14 shows the zone structure of bismuth films with a thickness of $20 \mathrm{BL}$, as well as the band connection diagram in the figure on the right [34]. This scheme corresponds to the non-trivial topology of the films. Near point $\bar{M}$ there is one conduction sub band separated by a gap with a valence sub band. The figure on the right shows that the branch, which corresponds to the surface states, is connected simultaneously with both the valence and conduction band, which corresponds to the non-trivial band structure.

\subsection{Changing Zones Close to the Film Edge}

In [36] the LDOS at the edge and at the centre of the terrace obtained by scanning tunnelling spectroscopy were compared. In both spectra, the tunnelling current began to grow only after a voltage above $0.9 \mathrm{~V}$. It is also worth noting that near the edge the intensity of the obtained spectra was higher. A convex peak was obtained in the middle of the terrace, which corresponds to valence band states. It was further shown that the position of the peak depends on the distance to the edge of the terrace, and as it turned out, the farther from the edge of the terrace the less voltage is needed to detect the peak. After $3.5 \mathrm{~nm}$ from the edge of the terrace, the position of the peak did not change. The authors hypothesize that the zone changes near the edge are due to the unsaturated bonds entering into a covalent bond with hydrogen, after which the charge accumulates near the edge of the film. Their second hypothesis is related to the presence of a dipole moment in the atoms protruding from the surface. What these two hypotheses have in common is that the charge accumulates near the corner of the film.

In [65], the $1 d$ dispersion along the direction $\mathrm{k}_{\mathrm{y}}$ is obtained. It is not quite clear why the $1 d$ dispersion is obtained. The authors of this paper, using angle-resolved photoemission spectroscopy (ARPES) and numerical calculations, have suggested that this effect is related to 
states near the BL edge. They also showed that there is a spin splitting near the edge of the film due to the Rash-ba effect.

\section{Conclusions}

In the initial stages of growth, bismuth films reproduce the structure of the substrate. This effect is noticeable from monolayers to ultrathin films up to $20 \mathrm{~nm}$ thick. When films up to $20 \mathrm{~nm}$ thick are obtained, not complete filling is observed, after which as the thickness increases, the voids are filled. At thicknesses above $50 \mathrm{~nm}$, all voids in the films are filled.

It was found that the optimal temperature for annealing is temperatures up to 240 degrees Celsius [37]. It has been shown that to obtain films with a large roughness value it is better to spray films at an angle [41], which can be useful for hydrophobic coatings. The films have different morphologies for different sputtering methods. Substrate temperature has a significant influence on the morphology of the film.

As the thickness of the films increases, the grain size increases. At the beginning of growth, the grains are round in shape. With further growth, the grains merge together and produce elongated grains. At about $40 \mathrm{~nm}$ thickness, the shape of the grains changes from spherical to polyhedral. The average grain size increases with annealing. In the temperature range from 18 to 100 degrees Celsius, the grain size did not increase significantly, while when reaching 100 degrees Celsius the size starts to increase rapidly. In the temperature range from 160 to 250 degrees Celsius, oscillations in grain size are noticeable, which may be caused by the oxidation of the films. As the film deposition rate increases, the grain sizes do not change significantly.

As the substrate temperature increases, the preferred bismuth film growth direction changes from (001) to (012). Given that bismuth films grow mostly along the direction of the (001) group on all considered substrates, it can be assumed that the textured growth is independent of the type of substrate. Further, it can be observed that the preferred direction changed with increasing temperature or with increasing energy of arriving particles on the substrate. Thus, textured growth is mainly dependent on the energy and mobility of the adatoms on the film surface.

When considering the resistance of thin films, there is a transition from semimetal to semiconductor. The first transition is related to quantum size effects, in which the resistance of thin films behaves like that of semiconductors, and thicker films behave like that of metals. The second transition is related to competing conduction mechanisms, namely metallic and semiconductors. 
Film conductivity is characterized by two transitions. Starting at low temperatures, where the metallic type of conductivity dominates, and with increasing temperature, the semiconductor type of conductivity begins to play the main role. Also for ultrathin films, the conductivity can be insignificant because of the not completely covered surface of a substrate. As the film thickness increases, the conductivity improves. As the film thickness increases further, there must be a critical thickness, at which the films will transit from a semiconductor state to a semimetallic state. Despite numerous studies of bismuth thin films, the exact film thickness at which this transition occurs is still unknown.

The Fermi surface consists of a hexagonal electron pocket near point $\bar{\Gamma}$. Farther in the direction from the hexagonal vertices, there are hole pockets, followed by electron pockets again. In bismuth films an anomalous Rashba effect is observed, which manifests itself in different values of spin polarization. Crossing the points $\bar{\Gamma}$ and $\bar{M}$ the polarization value is reversed. There is a separation of band near point $\bar{M}$. As the thickness decreases, the highest-level shifts downward and the distance between the subbands increases. At a thickness of $180 \mathrm{BL}$, the separation is no longer observed due to the small distance between the levels. Bismuth films have a non-trivial zone structure.

\section{REFERENCES}

1. S.Kochowski and A. Opilski, Thin Solid Films, 48, No. 3: 345 (1978); https://doi.org/10.1016/0040-6090(78)90014-7

2. A. Takayama, T. Sato, S. Souma, and T. Takahashi, Journal of Electron Spectroscopy and Related Phenomena, 201: 105 (2015);

https://doi.org/10.1016/j.elspec.2014.11.002

3. T. Hirahara, Journal of Electron Spectroscopy and Related Phenomena, 201: 98 (2015); https://doi.org/10.1016/j.elspec.2014.08.004

4. W. Kobayashi, Y. Koizumi, and Y. Moritomo, Applied Physics Letters, 100, No. 1: 011903 (2012); https://doi.org/10.1063/1.3673562

5. S. Ito, B. Feng, M. Arita, A. Takayama, R.-Y. Liu, T. Someya, W.-C. Chen, T. Limori, H. Namatame, M. Taniguchi, C.-M. Cheng, S.-J. Tang, F. Komori, K. Kobayashi, T.-C. Chiang, and I. Matsuda, Physical Review Letters, 117, No. 23: 236402 (2016); https://doi.org/10.1103/PhysRevLett.117.236402

6. A.A. Najim, Materials Science in Semiconductor Processing, 121: 105334(2021); https://doi.org/10.1016/j.mssp.2020.105334

7. T. Shin, Thin Solid Films, 666: 108 (2018); https://doi.org/10.1016/j.tsf.2018.09.037

8. G. Orozco-Hernández, J.J. Olaya, J.E. Alfonso, C.A. Pineda-Vargas, and C. Mtshali, Thin Solid Films, 628: 170 (2017);

https://doi.org/10.1016/j.tsf.2017.03.018

9. L. Du, D. Lu, J. Li, K. Yang, L. Yang, B. Huang, J. Yi, Q. Yi, L. Miao, X. Qi, C. Zhao, J. Zhong, and S. Wen, ACS Appl. Mater. Interfaces, 11, No. 39: 35863 (2019); https://doi.org/10.1021/acsami.9b10354 
10. J. Toudert, R. Serna, I. Camps, J. Wojcik, P. Mascher, E. Rebollar, and T.A. Ezquerra, The Journal of Physical Chemistry C, 121, No. 6: 3511 (2017); https://doi.org/10.1021/acs.jpcc.6b10331

11. K. Xu, L. Wang, X. Xu, S.X. Dou, W. Hao, and Y. Du, Energy Storage Materials, 19: 446 (2019);

https://doi.org/10.1016/j.ensm.2019.03.021

12. G. Bian, Z. Wang, X.-X. Wang, C. Xu, S. Xu, T. Miller, M.-Z. Hasan, F. Liu, and T.-C. Chiang, ACS Nano, 10, No.3: 3859 (2016);

https://doi.org/10.1021/acsnano.6b00987

13. E. Hashemi, R. Poursalehi, and H. Delavari, Materials Science in Semiconductor Processing, 89: 51 (2019);

https://doi.org/10.1016/j.mssp.2018.08.028

14. R. Borja-Urby, S.P. Paredes-Carrera, H. Viltres-Cobas, P. Santiago-Jacinto, F. Paraguay-Delgado, G. Herrera-Pйrez, L. Rendyn-Vбzquez, J.-C. Sбnchez-Ochoa, and D. Morales-Cruzf, Journal of Electron Spectroscopy and Related Phenomena, 237: 146891 (2019);

https://doi.org/10.1016/j.elspec.2019.146891

15. A. Goriachko, P.V. Melnik, A. Shchyrba, S.P. Kulyk, and M.G. Nakhodkin, Surface Science, 605, No. 19-20: 1771 (2011);

https://doi.org/10.1016/j.susc.2011.06.004

16. C. Wansorra, E. Bruder, and W. Donner, Acta Materialia, 200: 455 (2020); https://doi.org/10.1016/j.actamat.2020.09.030

17. A.J. Caruana, M.D. Cropper, and S.A. Stanley, Surface and Coatings Technology, 271: 8 (2015); https://doi.org/10.1016/j.surfcoat.2015.02.002

18. X. Zhang, W. Ren, F. Xin, and P. Shi, Journal of Alloys and Compounds, 614: 80 (2016); https://doi.org/10.1016/j.jallcom.2014.06.044

19. M. Wu, B. Xu, Y. Zhang, S. Qi, W. Ni, J. Hu, and J. Ma, Chemical Engineering Journal, 381: 122558 (2019); https://doi.org/10.1016/j.cej.2019.122558

20. Y. Ma, E. Ahlberg, Y. Sun, B.B. Iversen, and A.E.C. Palmqvist, Electrochimica Acta, 56, No. 11: 4216 (2011); https://doi.org/10.1016/j.electacta.2011.01.093

21. V.Y. Kolosov, A.A. Yushkov, and L.M. Veretennikov, Journal of Physics: Conference Series, 1115, No. 3: 032087 (2018); https://doi.org/10.1088/1742-6596/1115/3/032087

22. Z. Yang, Z. Wu, Y. Lyu, and J. Hao, InfoMat, 1, No. 1: 98 (2019); https://doi.org/10.1002/inf2.12001

23. M. Liu, J. Tao, C.-Y. Nam, K. Kisslinger, L. Zhang, and D. Su, Nano Letters, 14, No. 10: 5630 (2014); https://doi.org/10.1021/nl502208u

24. Y. Zabila, M. Marszalek, M. Krupinski, A. Zarzycki, and M. Perzanowski, Coatings, 11, No. 2: 175 (2021);

https://doi.org/10.3390/coatings11020175

25. C.M. Bedoya-Hincapiй, J. de la Roche, E. Restrepo-Parra, J.E. Alfonso, and J.J. Olaya-Florez, Ingeniare. Revista Chilena de Ingenierнa, 23, No. 1: 92 (2015); https://doi.org/10.4067/s0718-33052015000100011

26. E.S. Walker, S.R. Na, D. Jung, S.D. March, J.-S. Kim, T. Trivedi, W. Li, L. Tao, M.L. lee, K.M. Liechti, D. Akinwande, and S.R. Bank, Nano Letters, 16, No. 11: 6931 (2016);

https://doi.org/10.1021/acs.nanolett.6b02931 
27. F. Gity, L. Ansari, M. Lanius, P. Schьffelgen, G. Mussler, D. Grıtzmacher, and J.C. Greer, Applied Physics Letters, 110, No. 9: 093111 (2017); https://doi.org/10.1063/1.4977431

28. S.-Y. Yang, K. Chang, and S.S.P. Parkin, Phys. Rev. Research 2:022029(2020); https://doi.org/10.1103/PhysRevResearch.2.022029

29. Y. Hirai, N. Yoshikawa, H. Hirose, M. Kawaguchi, M. Hayashi, and R. Shimano, Physical Review Applied, 14, No. 6: 064015 (2020); https://doi.org/10.1103/physrevapplied.14.064015

30. L. Perfetti, J. Faure, E. Papalazarou, J. Mauchain, M. Marsi, M. O. Goerbig, A. Taleb-Ibrahimi, and Y. Ohtsubo, Journal of Electron Spectroscopy and Related Phenomena, 201: 60 (2015); https://doi.org/10.1016/j.elspec.2014.12.004

31. X. Wang, X. Yang, N. Shen, B. Wang, G. Ge, G. Wang, J. Wan, Applied Surface Science, 481, 1449-1458 (2019); https://doi.org/10.1016/j.apsusc.2019.03.251

32. A.V. Matetskiy, L.V. Bondarenko, A.Y. Tupchaya, D.V. Gruznev, S.V. Eremeev, A.V. Zotov, and A.A. Saranin, Applied Surface Science, 406: 122 (2017); https://doi.org/10.1016/j.apsusc.2017.02.023

33. M.C. Richter, J.-M. Mariot, M.A. Gafoor, L. Nicolan, O. Heckmann, U. Djukic, W. Ndiaye, I. Vobornik, J. Fujii, N. Barrett, V. Feyer, C.M. Schneider, and K. Hricovini, Surface Science, 651: 147 (2016); https://doi.org/10.1016/j.susc.2016.03.032

34. T.-R. Chang, Q. Lu, X. Wang, H. Lin, T. Miller, T.-C. Chiang, and G. Bian, Crystals, 9. No. 10: 510(2019); https://doi.org/10.3390/cryst9100510

35. K. Saito, H. Sawahata, T. Komine, and T. Aono, Physical Review B, 93, No. 4: 041301 (2016); https://doi.org/physrevb.93.041301

36. K. Nagaoka, T. Uchihashi, and T. Nakayama, Surface Science, 644: 41 (2016); https://doi.org/10.1016/j.susc.2015.09.008

37. T. Payer, C. Klein, M. Acet, V. Ney, M. Kammler, F.-J. Meyer zu Heringdorf, and M. Horn-von Hoegen, Thin Solid Films, 520, No. 23: 6905 (2012); https://doi.org/10.1016/j.tsf.2012.06.004

38. S.S. Hars, H.R. Sharma, J.A. Smerdon, S. Coates, K. Nozawa, A.P. Tsai, and R. McGrath, Surface Science, 678: 222 (2018); https://doi.org/10.1016/j.susc.2018.04.023

39. J. Toudert, R. Serna, C. Deeb, and E. Rebollar, Optical Materials Express, 9, No. 7: 2924 (2019); https://doi.org/10.1364/OME.9.002924

40. Y. Ahn, Y.-H. Kim, S.-I. Kim, and K.-H Jeong, Current Applied Physics, 12, No. 6: 1518 (2012); https://doi.org/10.1016/j.cap.2012.04.031

41. R.K. Jain, J. Kaur, S. Arora, A. Kumar, A.K. Chawla, and A. Khanna, Applied Surface Science, 463: 45 (2019); https://doi.org/10.1016/j.apsusc.2018.08.200

42. B. He, G. Tian, J. Gou, B. Liu, K. Shen, Q. Tian, Z. Yu, F. Song, H. Xie, Y. Gao, Y. Lu, K. Wu, L. Chen, and H. Huang, Surface Science, 679: 147 (2018); https://doi.org/10.1016/j.susc.2018.09.005

43. S.E. Rodil, O. Garcia-Zarco, E. Camps, H. Estrada, M. Lejeune, L. Bourja, and A. Zeinert, Thin Solid Films, 636: 384 (2017); https://doi.org/10.1016/j.tsf.2017.06.048 
44. N. Wang, Y.-X. Dai, T.-L. Wang, H.-Z. Yang, and Y. Qi, International union of crystallography journal, 7, No. 1: 49 (2020);

https://doi.org/10.1107/S2052252519015458

45. C. Sui, L. Di, and X. Qin, Vacuum, 166: 316 (2019);

https://doi.org/10.1016/j.vacuum.2019.05.026

46. J. Baron, P. Silva-Bermudez, and S. E. Rodil, MRS Proceedings, 1477: 40 (2012); https://doi.org/10.1557/opl.2012.1722

47. E.V. Demidov, V.M. Grabov, V.A. Kamarov, A.N. Krushelnitckii, A.V. Suslov, M.V.Suslov, Semiconductors, 53: 727 (2019); https://doi.org/10.1134/S1063782619060046

48. S.A. Stanley and M.D. Cropper, Applied Physics A, 120, No. 4: 1461 (2015); https://doi.org/10.1007/s00339-015-9337-3

49. A. Prados and R. Ranchal, Electrochimica Acta, 316: 113 (2019); https://doi.org/10.1016/j.electacta.2019.05.085

50. L. Yang, Y.-X. Zheng, S.-D. Yang, Z.-H. Liu, J.-B. Zhang, R.-J. Zhang, S.-Y. Wang, D.-X. Zhang, and L.-Y. Chen, Applied Surface Science, 421, No. B: 899 (2017); https://doi.org/10.1016/j.apsusc.2016.11.006

51. Megha, S. Rathod, A. Lakhani, and D. Kumar, AIP Conference Proceedings, 2100: 020155 (2019);

https://doi.org/10.1063/1.5098709

52. H. Emoto, Y. Ando, G. Eguchi, R. Ohshima, E. Shikoh, Y. Fuseya, T. Shinjo, and M. Shiraishi, Physical Review B, 93, No. 17: 174428 (2016);

https://doi.org/10.1103/physrevb.93.174428

53. C.F. Gallo, B.S. Chandrasekhar, and P. H. Sutter, Journal of Applied Physics, 34, No. 1: 144 (1963); https://doi.org/10.1063/1.1729056

54. W. Ning, F. Kong, Y. Han, H. Du, J. Yang, M. Tian, and Y. Zhang, Scientific Reports, 4, No. 1: 7086 (2014); https://doi.org/10.1038/srep07086

55. X. Sun, Z. Zhang, and M. S. Dresselhaus, Applied Physics Letters, 74, No. 26 : 4005 (1999); https://doi.org/10.1063/1.123242

56. N.S. Kablukova, V.A. Komarov, D.O. Skanchenko, E.S. Makarova, and E.V. Demidov, Semiconductors, 51, No 7: 879 (2017); https://doi.org/10.1134/s1063782617070168

57. A.D. Liao, M. Yao, F. Katmis, M. Li, S. Tang, J.S. Moodera, C. Opeil, and M.S. Dresselhaus, Applied Physics Letters, 105, No. 6: 063114 (2014); https://doi.org/10.1063/1.4893140

58. P. Kröger, D. Abdelbarey, M. Siemens, D. Lükermann, S. Sologub, H. Pfnür, and C. Tegenkamp, Physical Review B, 97, No. 4: 045403 (2018); https://doi.org/10.1103/physrevb.97.045403

59. D. Oller, G.E. Fernandes, J.H. Kim, and J. Xu, Physica B: Condensed Matter, 475: 117 (2015); https://doi.org/10.1016/j.physb.2015.07.023

60. Y. Liu and R.E. Allen, Physical Review B, 52, No. 3: 1566 (1995); https://doi.org/10.1103/physrevb.52.1566

61. Y. Ohtsubo and S. Kimura, New Journal of Physics, 18: 123015 (2016); https://doi.org/10.1088/1367-2630/18/12/123015

62. Y.M. Koroteev, G. Bihlmayer, E.V. Chulkov, and S. Blügel, Physical Review B, 77, No 4: 045428 (2018); https://doi.org/10.1103/physrevb.77.045428 
63. Y. Ohtsubo, L. Perfetti, M.O. Goerbig, P.L. Fèvre, F. Bertran, and A. TalebIbrahimi, New Journal of Physics, 15,No. 3: 033041 (2013); https://doi.org/10.1088/1367-2630/15/3/033041

64. Y. Fuseya, M. Ogata, and H. Fukuyama, Journal of the Physical Society of Japan, 84, No. 1: 012001 (2015); https://doi.org/10.7566/jpsj.84.012001

65. A. Takayama, T. Sato, S. Souma, T. Oguchi, and T. Takahashi, Physical Review Letters, 114, No. 6: 066402 (2015); https://doi.org/10.1103/physrevlett.114.066402

66. A. Takayama, T. Sato, S. Souma, T. Oguchi, and T. Takahashi, Nano Letters, 12, No. 4: 1776 (2012); https://doi.org/10.1021/nl2035018

67. A. Takayama, T. Sato, S. Souma, and T. Takahashi, Physical Review Letters, 106, No. 16: 166401 (2011); https://doi.org/physrevlett.106.166401

68. C. Zucchetti, F. Bottegoni, A. Calloni, G. Bussetti, L. Dut, M. Finazzi, and F. Ciccacci, Journal of Physics: Conference Series, 903: 012024 (2017); https://doi.org/10.1088/1742-6596/903/1/012024

69. M.-Y. Yao, F. Zhu, C.Q. Han, D.D. Guan, C. Liu, D. Qian, and J. Jia, Scientific Reports, 6, No. 1: 21326 (2016); https://doi.org/10.1038/srep21326

70. C.R. Ast and I. Gierz, Physical Review B, 86, No. 8: 085105 (2012); https://doi.org/10.1103/physrevb.86.085105

71. T. Hirahara, T. Nagao, I. Matsuda, G. Bihlmayer, E.V. Chulkov, Y.M. Koroteev, and S. Hasegawa, Physical Review B, 75, No. 3: 035422 (2007); https://doi.org/10.1103/physrevb.75.035422

72. T. Hirahara, T. Shirai, T. Hajiri, M. Matsunami, K. Tanaka, S. Kimura, S. Hasegawa, and K. Kobayashi, Physical Review Letters, 115, No. 10: 106803 (2015); https://doi.org/10.1103/physrevlett.115.106803

73. P. Hofmann, Progress in Surface Science, 81, No. 5: 191 (2006); https://doi.org/10.1016/j.progsurf.2006.03.001

Received 02.07.2021; in final version, 04.11.2021

В.Л. Карбівський, В.В. Заіка,

Л.І. Карбівська, Н.А. Курган, Н.О. Зуєва

Інститут металофізики ім. Г.В. Курдюмова НАН України, бульв. Академіка Вернадського, 36, 03142 Київ, Україна

\section{СТРУКТУРНІ ТА ФІЗИЧНІ ВЛАСТИВОСТІ УЛЬТРАТОНКИХ ПЛІВОК БІСМУТУ}

Плівки бісмуту є цікавим об'єктом для досліджень у зв'язку з великою кількістю ефектів, які виникають за товщини плівки менше 70 нм. Електронна зонна структура істотно змінюється залежно від товщини плівки. Отже, змінюючи товщину плівки, можна коригувати фізичні властивості матеріалу. Мета даної роботи - дати стислий опис основних структурних і фізичних властивостей плівок бісмуту. Спочатку розглядаються структурні властивості, а саме, морфологія, шерсткість, розміри наночастинок і текстурування, а далі йде опис транспортних 
властивостей і зонної структури. 3 транспортних властивостей розглянуто перехід напівметал-напівпровідник, який пов'язано з квантово-розмірним ефектом. Важливою також є двоканальна модель, яка уможливлює описати залежність питомого опору від температури. Зонна структура плівок бісмуту є найбільш цікавою частиною в зв'язку з аномальними ефектами, для яких все ще немає однозначного пояснення. 3 таких ефектів розглядаються: аномальна спінова поляризація, нетривіальна топологія, зміна зон поблизу краю плівки.

Ключові слова: тонкі плівки вісмуту, зонна структура, ефект Рашби, транспортні властивості, аномальна спінова поляризація. 